\title{
Peningkatan Nilai Tambah Ampas Kelapa Menjadi Aneka Produk Olahan Pangan di Desa Tirto Asri Kecamatan Taluditi Kabupaten Pohuwato
}

\author{
Siti Aisa Liputo ${ }^{1}$, Yuliana Bakari ${ }^{2}$ \\ ${ }^{1,2}$ Fakultas Pertanian Universitas Negeri Gorontalo, Jl. Jend. Sudirman No.6, Dulalowo Tim., Kota \\ Tengah, Kota Gorontalo, Gorontalo 96128, Indonesia \\ email: sitiliputo@ung.ac.id', yulianabakari@ung.ac.id ${ }^{2}$
}

\begin{abstract}
ABSTRAK
Kegiatan pengabdian ini bertujuan untuk meningkatkan pendapatan masyarakat petani dan pengolah minyak kelapa tradisional Desa Tirto Asri Kecamatan Taluditi Kabupaten Pohuwato, dengan metode Zero Waste yaitu pengolahan semua limbah yang dihasilkan menjadi produk yang inovatif dan berdaya jual. Dalam kegiatan KKN TEMATIK ini masyarakat dan petani akan diberi pengetahuan dan keterampilan mengenai produk olahan berbasis kelapa terutama produk-produk dari ampas kelapa sebagai media pembelajaran dan menumbuhkan rasa kepedulian mahasiswa terhadap permasalahan yang dihadapi oleh masyarakat. Metode yang digunakan dalam ini adalah menggunakan pendekatan partisipatif yaitu melaksanakan pendidikan dan pelatihan masyarakat dengan pihak akademisi (Dosen Pembimbing Lapang dan mahasiswa) dan pemerintah berperan sebagai fasilitator untuk dapat saling belajar, membagi pengetahuan dan pengalamannya. Lokasi kegiatan yaitu Desa Tirto Asri Kecamatan Taluditi Kaupaten Pohuwato. Jumlah mahasiswa yang dilibatkan pada kegiatan ini terdiri dari 31 orang. Sedangkan mitra kegiatan ini adalah kelompokkelompok tani di Desa Tirto Asri. Pelaksanaan kegiatan ini terdiri dari beberapa program yaitu program pengolahan ampas kelapa menjadi beberapa produk, seperti brownies, cookies dan bolabola coklat. Kegiatan program inti dilaksanakan di kantor desa pada tanggal 17 September 2020. Selain itu akan dilakukan pula program tambahan oleh mahasiswa KKN seperti penataan pekarangan dan penanaman tanaman sayur dan buah di pekarangan warga, pnempelan label penerima bantuan desa di rumah warga, kegiatan olahraga, dan beberapa kegiatan lainnya.
\end{abstract}

Kata kunci : ampas kelapa, limbah kelapa, brownies ampas kelapa, cookies

\begin{abstract}
This service activity aims to increase the income of traditional coconut oil farmers and processors in Tirto Asri Village, Taludity District, Pohuwato Regency, with the Zero Waste method, which is processing all the waste produced into innovative and marketable products. In this TEMATIK KKN activity, the community and farmers will be given knowledge and skills regarding coconut-based processed products, especially coconut dregs products as a learning medium and foster a sense of student concern for the problems faced by the community. The method used in this is to use a participatory approach, namely implementing community education and training with academics (field supervisors and students) and the government acting as a facilitator to be able to learn from each other, share knowledge and experiences. The location of the activity is Tirto Asri Village, Taluditi District, Pohuwato Regency. The number of students involved in this activity consisted of 31 people. Meanwhile, the partners of this activity are farmer groups in Tirto Asri Village. The implementation of this activity consists of several programs, namely a program to process coconut dregs into several products, such as brownies, cookies and chocolate balls. The core program activities will be carried out at the village office on September 17, 2020. In addition, additional programs will be carried out by KKN students such as arranging yards and planting vegetable and
\end{abstract}


fruit plants in residents' yards, affixing village aid recipient labels at people's homes, sports activities, and several other activities.

Keywords: coconut dregs, coconut waste, coconut dregs brownies, cookies

(C) 2019 Siti Aisa Liputo, Yuliana Bakari

Under the license CC BY-SA 4.0

Correspondence author: Siti Aisa Liputo, sitiliputo@ung.ac.id, Gorontalo, and Indonesia

\section{PENDAHULUAN}

Desa Tirto Asri merupakan salah sau desa terletak dibawah kaki gunumg di Kecamatan Taluditi Kabupaten Pohuwato. Luas Wilayah Desa Tirto Asri yaitu seluas 410,35 Ha yang didominasi oleh lahan perkebunana seluas 275,00 dan lahan persawahan seluas $51,00 \mathrm{Ha}$ sedangkan luas lahan pemukiman hanya seluas pemukiman $41,00 \mathrm{Ha}$.

Desa Tirto Asri memiliki potensi pertanian baik tanaman pangan, tanaman perkebunan, atau tanaman holtikultura. Tanaman perkebunan seperti kelapa, selapa sawit dan jagung mendominasi potensi pertanian di Desa Tirto Asri. Komoditas perkebunan utama yang diusahakan petani di Desa Tirto Asri adalah kelapa dengan luas lahan penanaman kelapa sebesar $\pm 224,00 \mathrm{Ha}$ ha yang diusahakan secara perkebunan rakyat. Namun potensi kelapa yang dimiliki oleh Desa Tirto Asrit ersebut belum dimanfaatkan secara optimal.

Kelimpahan produksi kelapa di Desa Tirto Asri membuat sebagian besar masyarakatnya mencari penghasilan melalui kelapa. Dari menanam kelapa sampai mengolahnya menjdai bahan baku kopra dan menjadi minyak kelapa klentik atau minyak kelapa tradisional. Pengolahan kelapa ditingkat petani di Desa Tirto Asri sebagian besar tertuju pada penanganan daging buah dengan produk yang dihasikan terbatas pada minyak klentik. Pemanfaatan kelapa yang hanya terfokus pada satu jenis produk saja kurang memberi nilai tambah bagi komoditas kelapa dan tidak berdampak pada perbaikan pendapatan petani. Produk-produk samping dari olahan kelapa yang masih memiliki nilai nutrisi yang tinggi khususnya ampas kelapa yang memungkinkan untuk dilakukan pengolahan selanjutnya sehingga memiliki nilai ekonomi yang tinggi. Namun potensi ini biasanya hanya dibuang 
begitu saja dan belum mendapat perhatian dari masyarakat di Desa Tirto Asri untuk dimanfaatkan.

Rendahnya pengetahuan masyarakat mengenai diversifikasi produk olahan ampas kelapa, membuat mereka membuang begitu saja hasil sampingan tersebut sehingga menjadi limbah. Oleh sebab itu dalam kegiatan ini akan meningkatkan pengetahuan bagi masyarakat di Desa Tirto Asri mengenai teknologi tepat guna yang bisa diterapkan pada limbah minyak klentik (Zero Waste) yaitu ampas kelapa menjadi produk-produk pangan dengan daya jual dan nilai ekonomi yang tinggi. Usaha pengolahan kelapa di Desa Tirto Asri oleh masyarakat dapat dilakukan sebagai upaya transfer informasi teknologi pengolahan kelapa melalui kegiatan pelatihan.

\section{METODE PELAKSANAAN}

Kegiatan ini dilakukan dengan menggunakan pendekatan partisipatif yaitu melaksanakan pendidikan dan pelatihan masyarakat dengan pihak akademisi (Dosen Pembimbing Lapang (DPL). Mahasiswa dan pemerintah berperan sebagai fasilitator untuk dapat saling belajar membagi pengetahuan dan pengalamannya. Pendekatan partisipatif adalah memberdayakan masyarakat agar mampu mendukung pembangunan sumber daya manusia secara berkelanjutan (Saragih. 2002 dalam Lay. dkk 2004). Selain itu paket teknologi pengolahan produk turunan kelapayang ditawarkan kepada masyarakat adalah teknologi tepat guna sehingga dapat diterapkan kepada masyarakat pedesaaan. Menurut Saragih (2002) dalam Lay.dkk 2004) bahwa teknologi tepat guna adalah inovasi teknologi yang memenuhi criteria (a) secara teknis teknologi dapat diterapkan oleh pengguna. (b) memberi nilai tambah dan insentif yang memadai. (c) dapat diterima oleh pengguna.dan (d) teknologi ramah lingkungan.

\section{HASIL DAN PEMBAHASAN}

Beberapa program yang dilakukan untuk mencapai hasil dari kegiatan KKN TEMATIK ini meliputi program pengolahan ampas kelapa menjai tepung kelapa kemudian diolah produk olahan seperti Kue kering dan brownies. Dalam 
pelaksanaan program ini, beberapa peralatan yang digunakan dalam proses pengolahan seperti oven, dan mixerakan diberikan kepada masyarakat.

Metode yang digunakan dalam melakukan pemberdayaan kelompok sasaran adalah metode partisipatif yang berbentuk pendidikan dan pelatihan mengenai proses pengolahan berbasis kelapa. Kegiatan pelatihan akan dilakukan oleh mahasiswa didampingi oleh dosen pembimbing lapangan. Langkah-langkah operasional untuk mengatasi permasalahan terdiri dari :

- Penyiapan ampas kelapa

- Pengolahan ampas kelapa menjai tepung ampas kelapa

- Pengolahan tepung ampas kelapa menjai kue kering dan brownies

- Proses pengemasan dan pelabelan hasil produk

- Penerapan Good Manufacture Process (GMP) dalam proses pengolahan

Mahasiswa dalam kegiatan ini mengambil porsi besar dengan volume pekerjaan sebanyak 144 jam Kerja Efektif Mahasiswa (JKEM) dalam sebulan. Rata-rata JKEM per hari adalah 4.8 jam sebagai acuan. Uraian tabel dalam bentuk program dan jumlah mahasiswa pelaksana dapat dilihat pada tabel berikut.

Tahapan persiapan yang dilakukan oleh mahasiswa yaitu melakukan pengorganisasian program kerja utama oleh peserta KKN TEMATIK dengan melakukan penyusunan kepanitiaan dan pembagian tanggung jawab masingmasing dalam melaksanakan kegiatan yang akan diselenggarakan oleh peserta KKN bekerjasama dengan perangkat-perangkat desa Karang Taruna danmasyarakat. Pada tahapan persiapan, berdasarkan koordinasi bersama dosen pembibing lapang, mahasiswa KKS mempersiapkan bahan baku utama yaitu ampas kepala yang telah dikeringkan. Persiapan bahan baku utama dilaksanakan dengan maksimal oleh mahasiswa mulai dari bekerjasama dengan masyarakat untuk mempersiapkan kelapa gekondongan, mengupas kelapa, memisahkan ampas kelapa, sampai pada melakukan penjemuran hingga mendapatkan ampas kelapa kering sesuai dengan kualitas bahan baku yang dibutuhkan. Sedangkan bahan baku tambahan, dipersiapkan oleh dosen pembimbing lapang untuk digunakan pada saat pelaksanaan program. Selain itu, kegiatan persiapan secara 
administrasi dan kelembagaan juga dillaksanakan oleh mahasiswa KKS-Tematik mulai dari koordinasi dengan aparat desa, membuat surat undangan pelaksaan kegiatan, mengudang masyarakat desa, mempersiapkan konsumsi untuk peserta serta mempersiapkan tempat pelaksanaan kegiatan.

Edukasi lannya menjelaskan kepada masyarakat tentang proses pengemasan dan pemasaran produk yang akan dihasilkan sehingga dapat langsung dijual oleh masyarakat setempat dan memberikan nilai tambah ekonomi bagi masyarakat. Setelah mendapatkan edukasi masyarakat diberikan pelatihan langsung dalam 3 kelompok untuk mengolah ampas kelapa menjadi produk brownies, coconut balls dan coconut cookies.
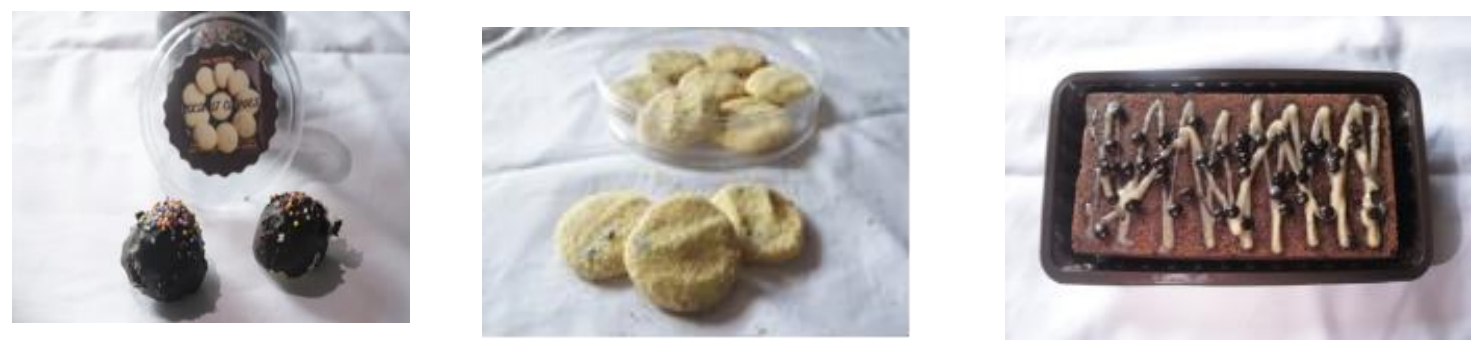

Gambar 1. Produk Olahan Ampas Kelapa

\section{KESIMPULAN}

Pelaksanaan program pengabdian ini telah berhasil memberikan tambahan pengetahuan bagi masyarakat desa Tirto Asri mengenai bagaimana mengolah limbah olahan kelapa khususnya ampas kelapa menjadi beberapa produk yang memeiliki nilai jual lebih tinggi seperti Brownies, cookies dan bola-bola coklat.

Kegiatan pengabdian ini diharapkan dapat memberikan bekal dan motivasi bagi masyarakat desa untuk mengembangkan usaha khususnya di bidang olahan pangan.

\section{UCAPAN TERIMAKASIH}

Ucapan terimakasih disampaikan kepada pihak Lembaga Penelitian dan Pengabdian Kepada Masyarakat (LPPM) UNG yang telah mendanai kegiatan ini. Juga disampaikan terimakasih yang sebesar-besarnya terhadap pihak pemerintah Desa TirtoAsri Kecamatan Taluditi beserta warga masyarakat yang telah bersedia 
menerima mahasiswa $\mathrm{KKN}$ dan telah banyak membantu serta memberikan dukungan hingga kegiatan ini bias terlaksana.

\section{DAFTAR PUSTAKA}

BPS. 2019. Kecamatan Taluditi. Taluditi Dalam Angka

Lay. A. . P.M Pasang dan D.J. Torar. 2004. Perkembangan Teknologi Pengolahan Minyak Kelapa. Monograf Pascapanen Kelapa Balitka Manado. ISBN 97998976-09

LPM.2015. Panduan Pelaksanaan KKS PENGABDIAN. LLPM Universitas Negeri Gorontalo.

Desa Tirto Asri. 2020. https;//tirtoasri.desa.id (website resmi) 